\title{
Definition, etiology, prevention and treatment of peri-implantitis - a review
}

\author{
Ralf Smeets ${ }^{1 *}$, Anders Henningsen ${ }^{1}$, Ole Jung ${ }^{1}$, Max Heiland ${ }^{1}$, Christian Hammächer ${ }^{2}$ and Jamal M Stein ${ }^{3}$
}

\begin{abstract}
Peri-implant inflammations represent serious diseases after dental implant treatment, which affect both the surrounding hard and soft tissue. Due to prevalence rates up to $56 \%$, peri-implantitis can lead to the loss of the implant without multilateral prevention and therapy concepts. Specific continuous check-ups with evaluation and elimination of risk factors (e.g. smoking, systemic diseases and periodontitis) are effective precautions. In addition to aspects of osseointegration, type and structure of the implant surface are of importance. For the treatment of peri-implant disease various conservative and surgical approaches are available. Mucositis and moderate forms of peri-implantitis can obviously be treated effectively using conservative methods. These include the utilization of different manual ablations, laser-supported systems as well as photodynamic therapy, which may be extended by local or systemic antibiotics. It is possible to regain osseointegration. In cases with advanced peri-implantitis surgical therapies are more effective than conservative approaches. Depending on the configuration of the defects, resective surgery can be carried out for elimination of peri-implant lesions, whereas regenerative therapies may be applicable for defect filling. The cumulative interceptive supportive therapy (CIST) protocol serves as guidance for the treatment of the peri-implantitis. The aim of this review is to provide an overview about current data and to give advices regarding diagnosis, prevention and treatment of peri-implant disease for practitioners.
\end{abstract}

Keywords: Peri-implantitis, Peri-implant disease, Review, Periodontal disease, Mucositis, Peri-implantitis therapy, Epidemiology, Etiology

\section{Introduction}

Dental implants have become an indispensable established therapy in dentistry in order to replace missing teeth in different clinical situations. Success rates of $82,9 \%$ after 16 years follow-up have been reported [1]. Under care and attention of indications, anatomical and intra-individual limiting factors, insertion of dental implants seems to represent a "safe" treatment option. Nevertheless, in the last decades increasing evidence raised on the presence of peri-implant inflammations representing one of the most frequent complications affecting both the surrounding soft and hard tissues which can lead to the loss of the implant. Therefore, strategies for prevention and treatment of peri-implant disease should be integrated in modern rehabilitation concepts in dentistry. The present review gives an updated overview

\footnotetext{
*Correspondence: r.smeets@uke.de

${ }^{1}$ Department of Oral and Maxillofacial Surgery, University Medical Center Hamburg-Eppendorf, Martinistr. 52, 20246 Hamburg, Germany

Full list of author information is available at the end of the article
}

on the pathogenesis, etiology, risk factors and prevention of peri-implantitis, but also on actual recommendations in treatment and therapy options.

\section{Review}

\section{Definition und pathogenesis}

In analogy to gingivitis and periodontitis affecting the periodontium of natural teeth, an inflammation and destruction of soft and hard tissues surrounding dental implants is termed as mucositis and peri-implantitis [2-4]. Thereby, transitions are often fluent and not clinically clearly separable [5].

Mucositis describes a bacteria-induced, reversible inflammatory process of the peri-implant soft tissue with reddening, swelling and bleeding on periodontal probing (Figure 1) [2-6]. These are typical signs, but they are sometimes not clearly visible. Furthermore, bleeding on probing (BOP) might be an indicator for peri-implant disease, but sufficient evidence according to the predictive value of BOP is still lacking [7]. 


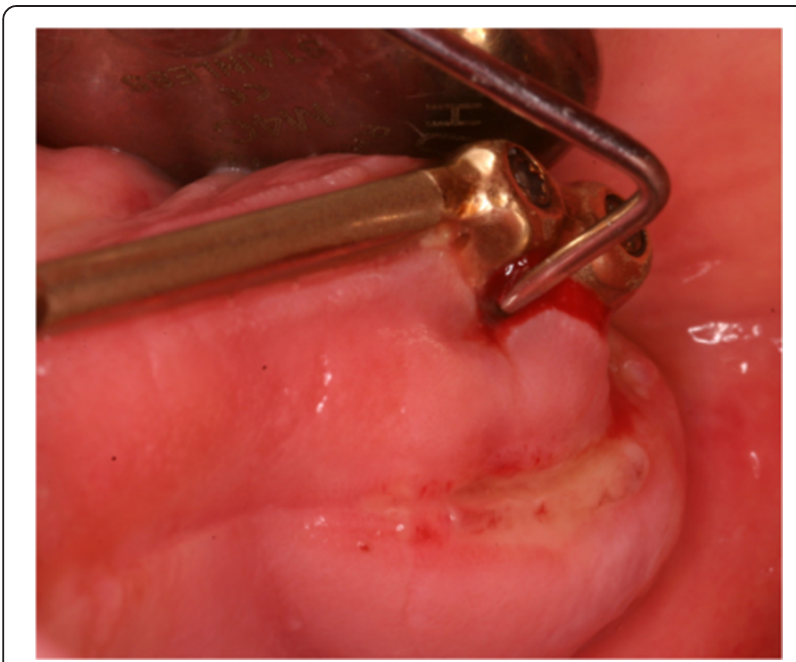

Figure 1 Peri-implantitis with increased probing depth $(12 \mathrm{~mm})$.

In contrast to mucositis, peri-implantitis is a progressive and irreversible disease of implant-surrounding hard and soft tissues and is accompanied with bone resorption, decreased osseointegration, increased pocket formation and purulence [2-6]. Bleeding on probing, bone loss and deep probing depths may have other reasons than inflammation, e.g. too deep insertion of the implant [8]. Moreover, type and shape oft the implant, connection type, abutment and suprastructure material and the type of prosthetic suprastructure affect the peri-implant soft and hard tissues [7].

Depending on the configuration of the bony defect, Schwarz et al. distinguished between an intraosseous class I defect and a supra-alveolar class II defect in the crestal implant insertion area [5]. Spiekermann characterized the type of bone resorption into horizontal (class I), key-shaped (class II), funnel- and gap-like (class III a, b) as well as horizontal-circular (class IV) forms [9]. However, it is not possible to conclude progression and prognosis criteria from these classifications.

On a microscopic and molecular level, striking differences between peri-implant tissue and intact periodontium can be determined (Table 1). Due to the reduced vascularization and parallel orientation of the collagen fibres, peri-implant tissues are more susceptible for inflammatory disease than periodontal tissues. This phenomenon can be verified immunohistochemically through increased formation of inflammatory infiltrate, nitric oxide 1/3, VEGF, lymphocytes, leukocytes and Ki67 [10]. Besides, in analogy to periodontitis the level of matrix-metalloproteinases (MMP), such as MMP-8, is increased up to $971 \%$ in peri-implant lesions. The latter can be used for disgnostic purposes [11-13].

A differentiation of peri-implantitis to other inflammatory periodontal processes cannot be made on the basis of human saliva by markers such as osteocalcin, tartrate-resistant acid phosphatase (TRAP), dickkopfrelated protein-1 (DKK-1), osteoprotegerin (OPG) and cathepsin K (CatK) $[9,14]$.

\section{Etiology and epidemiology}

There are several reports on the prevalence of mucositis and peri-implantitis that differ between $5 \%$ and $63.4 \%$. This enormous range is mainly based on varying study designs and population sizes with different risk profiles and statistic profiles [5,15-18].

Zitzmann et al. quantified the incidence of the development of peri-implantitis in patients with a history of periodontitis almost six times higher than in patients with no history of periodontal inflammation [3]. After 10 years, $10 \%$ to $50 \%$ of the dental implants showed signs of peri-implantitis $[19,20]$. Based on the Consensus Report of the Sixth European Workshop in Periodontology, Lindhe \& Meyle reported an incidence of mucositis of up to $80 \%$ and of peri-implantitis between $28 \%$ and $56 \%[21]$.

However, the prevalence of peri-implant diseases, evaluated recently by Mombelli et al., revealed peri-implantitis in $20 \%$ of all implanted patients and in $10 \%$ of all inserted implants. Although this percentage has to be interpreted with caution because of the variability of the analyzed studies [7], it underlines the fact that bone remodeling processes often result in marginal bone loss during the first weeks after abutment connection which cannot be regarded as peri-implantitis. This led to the recommendation to take a radiograph after insertion of the suprastructure and to consider it as a basis for any future assessment of peri-implant bone loss.

Frequently, a spectrum of pathogenic germs can be detected such as Prevotella intermedia, Prevotella nigrescens, Streptococcus constellatus, Aggregatibacter actinomycetemcomitans, Porphyromonas gingivalis, Treponema denticola and Tannerella forsythia [3,22]. Rams et al. revealed 71.7\%

Table 1 Comparison of peri-implant mucosa with physiological periodontium [3,5]

\begin{tabular}{cc}
\hline Peri-implant mucosa & Physiological periodontium \\
\hline Desmosomes and hemidesmosomes of epithelium and junctional epithelium (biological width) are linked with the contact surface & Anchoring system of root cementum, alveolar bone and desmodontic fibers \\
Subepithelially more collagen fibers and less fibroblasts/vessels & Subepithelially more fibroblasts and vessels \\
Parallel collagen fibers in relation to implant surface & Dentogingival, dentoperiostal, circular and transseptal fiber orientation \\
\hline
\end{tabular}


resistance to at least one antimicrobial substance in a group of 120 patients [22]. Peri-implantitis is a poly-microbial anaerobic infection [23]. However, in contrast to periodontitis, peri-implantitis lesions harbor bacteria that are not part of the typical periodontopathic microbiota. In particular, Staphylococcus aureus appears to play a predominant role for the development of a peri-implantitis. This bacterium shows an high affinity to titanium and has according to the results of Salvi et al. a high positive (80\%) and negative (90\%) predictive value [24]. As another beneficial cause, smooth implant surfaces in comparison to rough surfaces can accelerate the peri-implant inflammation $[10,17,25]$.

\section{Risk factors and prevention}

Implant loss may occur as "early implant loss" up to one year after implant insertion and "delayed implant loss" with a time period of more than one year after implant insertion [3]. The following factors or circumstances have been reported as risk factors for the development of peri-implantitis $[5,6,16,26-33]$ :

- Smoking with additional significantly higher risk of complications in the presence of an positive combined IL-1 genotype polymorphism.

- History of periodontitis.

- Lack of compliance and limited oral hygiene (including missing checkups).

- Systemic diseases (e.g. maladjusted diabetes mellitus, cardiovascular disease, immunosuppression).

- Iatrogenic causes (e.g. "cementitis”).

- Soft tissue defects or poor-quality soft tissue at the area of implantation (e.g. lack of keratinized gingiva).

- History of one or more failures of implants.

Studies indicate smoking as the greatest identifiable and most often cited risk factor for peri-implant disease followed by a history of periodontitis. Both are related to higher prevalences of peri-implantitis [7]. The presence of periodontitis or cigarette smoking increased the risk for peri-implantitis up to 4.7-fold as reported by Wallowy et al. [6]. Moreover, smoking has been shown to be a predictor for implant failure [31]. In a recent meta-analysis smoking increased the annual rate of bone loss by $0.16 \mathrm{~mm} /$ year and represented the main systemic risk factor [34]. The extent of osseointegration as well as the oral hygiene around dental implants was found to be reduced among smokers [35]. It is commonly accepted that the outcome of almost all intraoral therapeutic parameters are negatively affected by smoking although not in all previous studies a positive correlation between peri-implantitis and tobacco smoking could be found $[36,37]$. Evidence of predictors for implant success such as gender or age could not be found but for the jaw of treatment (maxillary versus mandibular implants). In a study by Vervaeke et al. maxillary implants were at a significantly higher risk for peri-implant bone loss compared to mandibular implants [31]. Bone augmented areas could not be determined as risk factors for implant failure or increased peri-implant disease [38].

Across an observation period of 10 years in a group of patients with periodontitis, the previously eliminated bacterial strains of Aggregatibacter actinomycetemcomitans and Porphyromonas gingivalis could again be detected in the oral mucosa [3]. Prevotella intermedia was, however, continuously evident. This indicates a niche survival of bacteria after tooth extraction with recurrence of the same microflora after a short period of time. In particular, attention should be paid to the remaining teeth with periodontitis as a potential source of infection. Therefore, the type of dentition (edentulous versus partially edentulous) may influence the colonization of peri-implant tissues with periodontal pathogens [38].

The impact of keratinized gingiva around dental implants has been controversially discussed, but most studies emphasize the importance of an adequate zone of keratinized tissue surrounding implants [39-41]. The so called "cementitis" may be regarded as the most important identifiable iatrogenic risk factor since its first description by Wilson et al. in 2009 [42]. The latter group revealed that residual dental cement in a group of patients with clinical or radiographic signs of peri-implant disease was present in $81 \%$ of the sites. After its removal, clinical signs were absent in $74 \%$ of the affected sites. Korsch et al. found that the removal of cement remnants led to a decrease of the inflammatory response by almost $60 \%$ [43]. Linkevizius et al. examined the manifestation of peri-implantitis in a group of patients with present cement remnants. In those who had a history of periodontitis, peri-implantitis was found in $100 \%$ of the patients, whereas cement remnants in patients with no previous periodontal disease ended up in $65 \%$ peri-implantitis manifestations [30]. Another preventive arrangement regarding antibacterial precautions are internal connections with inward located microgap, which should be preferred. [6].

Peri-implant probing is recommended to be carried out carefully with a minimal probing force. However, the so-called platform switch (abutment is located horizontally between implant and crown) can complicate probing and, thus, hide the true extension of peri-implantitis $[3,5,17,26,44]$. Nevertheless, studies have indicated that platform switch might be an important protective factor against peri-implant disease [45].

Implant loss can be differentiated on the basis of the following additional factors [3,5,6,46-49]:

- Overloading of the implant,

- Faults in material and techniques, 
- Poor bone quality at the implant area,

- Systemic diseases and drug therapies, which inhibit bone modulations according to "Wolff's law" (bone density and strength increase with stress - and vice versa).

Thus, implants of more than $10 \mathrm{~mm}$ length in square thread design show higher success rates than shorter implant lengths or shapes without thread or buttress thread $[48,49]$. Also rough implant surfaces of more than 2 microns seem to feature better osseointegration than smooth (<0.5 microns) or moderate surfaces $(1-2$ microns) [17].

Development of strengths in the temporomandibular joint of more than 1300 Newton may shift the implants in the first few months of healing up to 100 microns by presence of sagittal forces acting from an average of 50 Newton [46]. These average reference forces even increase to 87 Newton when articulation angles up to $60^{\circ}$ in horizontal axis.

In addition to patient training sessions for optimal oral hygiene, preventive strategies such as professional tooth and implant cleaning as well as individually continuous peri-implant examinations (probing status) should be considered in order to prevent peri-implant diseases (Table 2) [6]. Attention has to be paid, in particular, to the reduction of the above-mentioned risk factors such as heavy smoking or diabetes mellitus.

As part of a holistic therapy, so-called reference parameters ("hour zero") and clearly determined control procedures have to be assessed with adequate documentation. Radiographs should be taken pre-, intraand post operatively in order to get information about the implantation site in which peri-implant inflammation will be detectable as brightening zones indicating increased bone resorption [6].

Prevention of peri-implant disease starts with a sufficient and structured planning including individual evaluation and minimization of risk factors (smoking, compliance, oral hygiene, periodontal disease, systemic diseases), establishment of optimal soft and hard tissue conditions, the choice of the correct implant design followed by a maximally atraumatic approach and regular clinical examinations with a periodontal probing status.

\section{Therapy}

The treatment of peri-implant infections comprises conservative (non-surgical) and surgical approaches. Depending on the severity of the peri-implant disease (mucositis, moderate or severe peri-implantitis) a nonsurgical therapy alone might be sufficient or a step-wise approach with a non-surgical therapy followed by a surgical treatment may be necessary.

\section{Therapy of mucositis}

One of the main aims of peri-implant therapy is to detoxify the contaminated implant surface. In the presence of peri-implant mucositis, non-surgical methods are appropriate and sufficient for detoxification. These include mechanical implant cleaning with titanium or plasticcurettes, ultrasonics or air polishing. Moreover, photodynamic therapy as well as local antiseptic medication (chlorhexidinglukonate, hydrogen peroxide, sodium percarbonate, povidone-iodine) may support the antimicrobial therapy.

In two randomized clinical trials Heitz-Mayfield et al. and Hallström et al. were not able to prove any benefits in reduction of pocket depth, plaque index or purulency when adjuvant antimicrobial therapy (chlorhexidine and azithromycine) was used in addition to mechanical therapy only [50,51]. Reductions of the bleeding index were explained by the general improvement of oral hygiene with reference to the potential importance of guidelines and treatment protocols [50-52]. The establishment of an adequate oral hygiene should, therefore, be considered as key issue of the prevention of peri-implant infections. Besides, a maintenance program with regular evaluation of the peri-implant probing depths, supportive professional implant cleaning and oral hygiene training should be integral part of every post-operative care after implant insertion $[2,6]$.

\section{Therapy of peri-implantitis}

Most of the published strategies for peri-implantitis therapy are mainly based on the treatments used for teeth with periodontitis. The reason is that the way of bacterial colonization of dental and implant surfaces follow similar principles, and it is commonly accepted that the microbial biofilm plays an analogous role in the development of peri-implant inflammation [53]. For the

Table 2 Numbers of check-ups (cu) annually for different patient collectives

\begin{tabular}{lccc}
\hline & $\mathbf{c u}=\mathbf{1}$ & $\mathbf{c u}=\mathbf{2}$ & $\mathbf{c u}>\mathbf{3}$ \\
\hline Oral hygiene and hygienic ability of the implant & well & middle & bad \\
Smoking status & $/$ & in history & in presence \\
Periodontitis, mucositis (with history) & $/$ & $/$ & in presence \\
Other risk factors & $/$ & $/$ & e.g. systemic diseases, history of an non-successful implant insertion \\
\hline
\end{tabular}


treatment of peri-implantitis, both conservative (nonsurgival) as well as surgical therapies can be applied. Thereby, the surgical treatments can be done using resective or regenerative approaches [54-59].

\section{Conservative therapy}

In addition to medication and manual treatment (e.g. with curettes, ultrasonic and air polishing systems) innovative techniques such as laser-supported and photodynamic therapy methods are recently described as conservative therapy options.

\section{Manual treatment}

Basic manual treatment can be provided by teflon-, carbon-, plastic- and titanium curettes (Figure 2).

Due to the fact that therapy with conventional curettes is able to modify the implant surface and can roughen the surface, it has been recommended that the material of the tip should be softer than titanium [60,61]. It is possible to reduce bleeding on probing scores by cleaning with piezoelectric scalers as well as with hand instruments, and no differences have been found between these methods concerning reduction of bleeding on probing, plaque index and probing depths after at least 6 months $[62,63]$.

As to the above-mentioned methods, the efficacy of ultrasonic curettage seems to underly the use of air polishing systems (Figure 3) [5,62,64-68]. Persson et al. and Renvert et al. experienced significantly lower numbers of bacteria with partial reduction of plaque and bleeding scores after mechanical curettage, while Schwarz et al. reported $30 \%-40 \%$ less residual biofilm areas by using ultrasonic methods $[5,63,66]$. Depending on the surface topography of the implants, Louropoulou et al. recommend different therapeutic methods (Table 3).

The results of air polishing systems are depending on the used medium and are significantly better in the following order: hydroxylapatite/tricalcium phosphate >

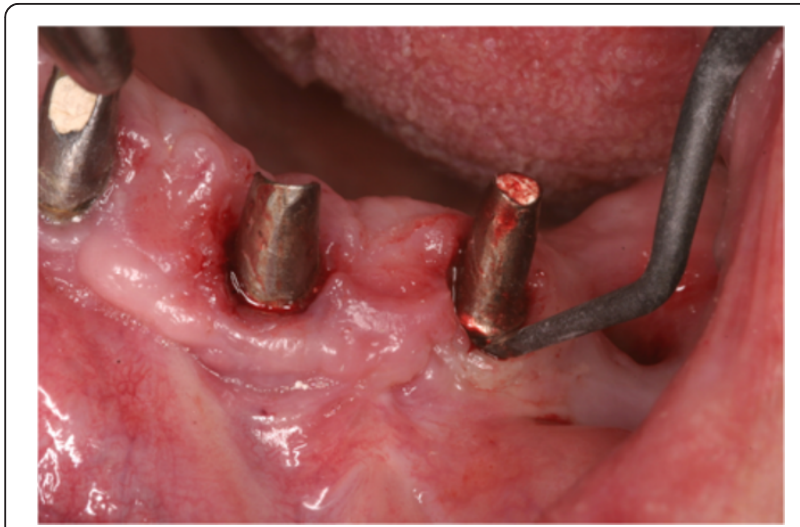

Figure 2 Conservative therapy - example of the use of a carbone curette.

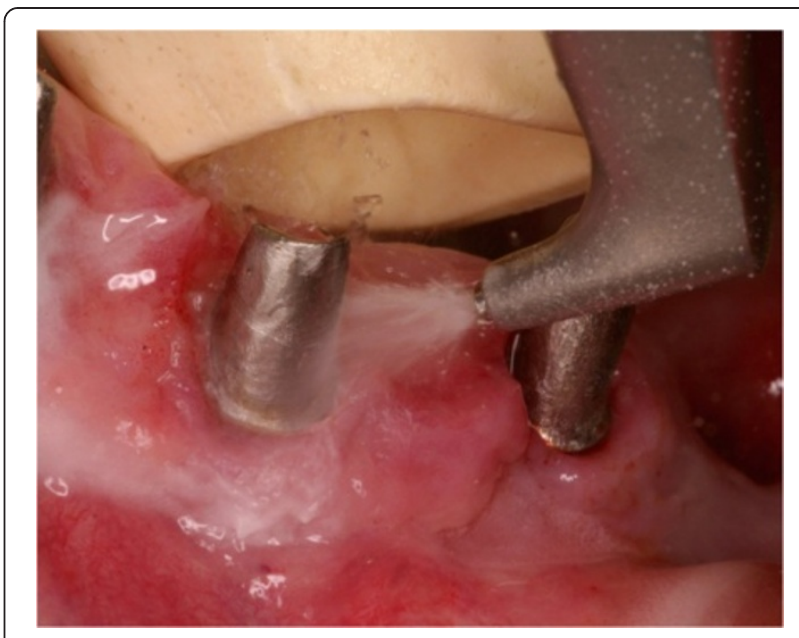

Figure 3 Conservative therapy - detoxification using an air polishing device with glycin powder.

hydroxylapatite $>$ glycine $>$ titanium dioxide $>$ water and air (control group) > phosphoric acid [64]

An abrasive air polishing medium can modify the surface of implants. After air powder treatment cell attachment and cell viability still showed sufficient levels, but cell response was decreased compared with sterile surfaces $[64,65,67]$. The extent of re-osseointegration of titanium implants after air polishing therapy has been reported between $39 \%$ and $46 \%$ with increased clinical implant attachment and pocket depth reduction [65]. The occurrence of bleeding on probing, one of the qualitative parameters in the presence of a peri-implantitis, could be significantly reduced [67].

\section{Drug therapy}

There are numerous in vitro and in vivo studies on the application of medicaments as part of the treatment of mucositis and peri-implantitis. However, due to differences in the design of all studies, comparison of these studies is difficult. The following therapies can be distinguished:

- Antiseptic rinses in relation to different parameters.

- Application of systemic and locally delivered antibiotics in relation to pocket depth or different parameters.

In a review by Javed et al., summarizing nine studies, systemic and local antibiotic applications (e.g. tetracycline, doxycycline, amoxicillin, metronidazole, minoxicycline hydrochloride, ciprofloxacin, sulfonamides + trimethoprim) led to significant reductions of pocket depths in a period between one and six years [69]. Moura et al. noticed the same for resorbable doxicycline releasing nanospheres in local application over a period of 15 months [70]. Leonhardt et al. noticed an overall 
Table 3 Qualitative effectiveness (x: yes/o: no) of different cleaning methods depending on implant surface [68]

\begin{tabular}{lccc}
\hline & Smooth surface & Sandblasted and acid-etched surface (SLA) & Plasma sprayed surface \\
\hline Rubber cap & 0 & 0 & 0 \\
Metalic curette, rotating titanium brush & 0 & $\times$ & $\times$ \\
Plastic curette & 0 & 0 & 0 \\
Ultrasonic systems with metalic tips & $\times$ (polished) & & $\times$ \\
Ultrasonic systems with plastic tips & 0 & $\times$ & $\times$ \\
Air polishing & $\times$ & & \\
\hline
\end{tabular}

success rate of $58 \%$ when treating peri-implantitis with surgical debridement and the use of various antibiotics and combinations of them (including clindamycin, amoxicillin + metronidazole, tetracycline, ciprofloxacin) [71].

Astasov-Frauenhoffer et al. were able to prove complete growth-inhibiting effects of amoxicillin and metronidazole on Streptococcus sanguinis, Porphyromonas gingivalis and Fusobacterum nucleatum apart from each other, but the combination was found to be more efficient than metronidazole alone [72]. Comparing local antibiotic therapy with photodynamic therapy, Bassetti et al. presented no differences in reduction of pocket depths or reduction of the number of bacteria in the periodontal pockets [73]. Grapefruit juice, known as antioxidant, had only a bacteriostatic effect against Streptococcus aureus [74]. But is has to be considered that depending on the type, bacteria demonstrate different high resistances against antibiotics (Table 4). Submucosal biofilm specimens were cultured from patients with peri-implantitis and after in vitro testing for susceptibility especially the combination of amoxicillin and metronidazole showed significant lower resistances (6.7\%) [22].

Application of chlorhexidine resulted in the reduction of pocket depths, a higher implant adhesion and general weakening of inflammation measured by the level of the inflammatory markers IL-1 beta, VEGF and PGE-2 in various studies [75-77]. Compared to minocycline microsphere application repeated every three months [78], the treatment with $1 \%$ chlorhexidine gel resulted in significantly less reduced pocket depths after 12 months. Concerning tissue engineering, Lan et al. demonstrated a continuous release-kinetic of metronidazole for 30 days

Table 4 Antibiotic resistance of Prevotella intermedia, Prevotella nigrescens and Streptococcus constellatus (n = 120) [22]

\begin{tabular}{lc}
\hline Antibiotic & Resistance \\
\hline Clindamycin & $46,7 \%$ \\
Amoxicillin & $39,2 \%$ \\
Doxycycline & $25 \%$ \\
Metronidazole & $21,7 \%$ \\
Amoxicilin \& metronidazol & $6,7 \%$ \\
\hline
\end{tabular}

using a Poly- $\varepsilon$-Caprolacton/Alginat-ring [79]. Hou et al. incorporated fluorouracil into cylindrical poly- $\varepsilon-$ caprolactone-implants of different diameters [80].

Local or systemic antibiotics are an additional therapy option. In combination with other conservative or surgical treatments it results in more efficient reductions of clinical peri-implantitis symptoms [81]. Just administration of antibiotics is no treatment option.

\section{Laser therapy}

By means of a bactericide mode of action, $\mathrm{CO}_{2}$, Diode-, Er:YAG- (erbium-doped: yttrium-aluminum-garnet) and Er,Cr:YSGG- (erbium, chromium-doped: yttriumscandium-gallium-garnet) lasers are used in the treatment of peri-implant diseases with increasing frequency. Minimal absorption and reverberations must be ensured with the purpose to protect implant and tissue. Er:YAG and Er, $\mathrm{Cr}$ :YAG with a wavelength of 3 microns can reduce biofilms up to $90 \%$ but in contrast to most mechanical therapies any biological compatibilities and cell stimulatory properties can't be re-induced $[5,82,83]$. Treatment with a $\mathrm{CO}_{2} 308 \mathrm{~nm}$ excimer laser, however, led mainly and efficiently to satisfactory results in an anaerobic bacteria spectrum [84].

In comparison to mechanical methods (plastic curettes), treatments with an Er:YAG laser led to significantly better results in terms of bleeding at peri-implantitis. However, both methods showed no significant differences in changes of pocket depths, clinical attachment level, plaque index and gingival recessions, although in both groups these parameters were improved [85].

Persson et al. examined the effectiveness of Er:YAG lasers compared to an air polishing system in a randomized clinical trial with 42 patients over 6 months [86]. Except for different reducing effects on specific bacteria strains after one month (Er:YAG: Fusobacterium nucleatum; air polishing system: Pseudomonas aeruginosa, Staphylococcus aureus and Peptostreptococcus anaerobius) there were no long term-reducing effects shown after 6 months. In a recent study Mailoa et al. showed that laser therapy resulted in similar reductions of probing depths when compared to other decontamination methods [87]. Although there is only few data in comparison to manual and surgical therapy, laser therapy as 
a treatment option has to be considered as an adjunct. Further studies are needed to evaluate the profit of laser therapy in peri-implantitis treatment.

\section{Photodynamic therapy}

Photodynamic therapy generates reactive oxygen species by multiplicity with help of a high-energy single-frequency light (e.g. diode lasers) in combination with photosensitizers (e.g. toluidine blue). In a wave length range of 580 to $1400 \mathrm{~nm}$ and toluidine blue-concentrations between 10 and $50 \mathrm{ug} / \mathrm{ml}$, photodynamic therapy generates bactericide effects against aerobic and anaerobic bacteria (such as Aggregatibacter actinomycetemcomitans, Porphyromonas gingivalis, Prevotella intermedia, Streptococcus mutans, Enterococcus faecalis) $[5,88,89]$. The only prospective randomized clinical trail by Basseti et al. covered 12 months of follow-up. After manual debridement by titanium curettes and glycine air powder treatment half of the patients received adjunctive photodynamic therapy and the other half received minocycline microspheres into implant pockets. After 12 months, the number of periopathogenic bacteria and level of IL-1 $\beta$ decreased significantly in both groups without significant differences between them [73]. In a study by Deppe et al. regarding to the effectiveness of phototherapy on a moderate and severe peri-implantitis, both clinical attachment and bleeding index were significantly reduced suggesting that severe cases still resulted in bone resorption [90].

As a recommendation, photodynamic therapy has to be considered as an additional treatment option. Due to the fact that it is a relatively new approach, the data is rare and there are no long-term-studies available. Further evaluations and prospective clinical trials are needed for evaluation.

\section{Surgical therapy}

The surgical therapy combines the concepts of the already mentioned non-surgical therapy with those of resective and/or regenerative procedures. The indication for the appropriate treatment strategy has been demonstrated in patient studies leading to the development of the "cumulative interceptive supportive therapy (CIST)" concept [91-93]. In 2004 it was modified and called AKUT-concept by Lang et al. (Table 5) [93]. The basis of this concept is a regular recall of the implanted patient and repeated assessment of plaque, bleeding, suppuration, pockets and radiological evidence of bone loss.

A further commonly accepted concept by Zitzmann et al. is referred to systematic periodontitis therapy. During the initial phase oral hygienic conditions have to be improved and mechanical cleaning and local antiinfective treatments are applied, if necessary. If non-surgical treatment fails, surgical intervention with open debridement and resective or regenerative therapy is recommended [3].
Table 5 AKUT-protocol by Lang et al. [93]

\begin{tabular}{|c|c|c|}
\hline Stage & Result & Therapy \\
\hline & $\begin{array}{l}\text { Pocket depth }(P D)< \\
3 \mathrm{~mm} \text {, no plaque or } \\
\text { bleeding }\end{array}$ & No therapy \\
\hline A & $\begin{array}{l}\mathrm{PD}<3 \mathrm{~mm} \text {, plaque and/ } \\
\text { or bleeding on probing }\end{array}$ & $\begin{array}{l}\text { Mechanically cleaning, polishing, } \\
\text { oral hygienic instructions }\end{array}$ \\
\hline $\mathrm{B}$ & $\begin{array}{l}\text { PD 4-5 mm, radiologically } \\
\text { no bone loss }\end{array}$ & $\begin{array}{l}\text { Mechanically cleaning, polishing, } \\
\text { oral hygienic instructions plus local } \\
\text { antiinfective therapy (e.g. CHX) }\end{array}$ \\
\hline C & $\begin{array}{l}\mathrm{PD}>5 \mathrm{~mm} \text {, radiologically } \\
\text { bone loss }<2 \mathrm{~mm}\end{array}$ & $\begin{array}{l}\text { Mechanically cleaning, polishing, } \\
\text { microbiological test, local and } \\
\text { systemic antiinfective therapy }\end{array}$ \\
\hline D & $\begin{array}{l}\mathrm{PD}>5 \mathrm{~mm} \text {, radiologically } \\
\text { bone loss }>2 \mathrm{~mm}\end{array}$ & Resective or regenerative surgery \\
\hline
\end{tabular}

The concept of Schmage follows the CIST-protocol but recommends always mechanical and local disinfective treatments in stage A and B. Intervention should be performed if probing depths exceed $5 \mathrm{~mm}$ or are progressive as well as under occurrence of local inflammation signs [94].

\section{Resective therapy}

In analogy to periodontitis, resective surgery has been shown to be effective in reduction of BOP, probing depths and clinical signs of inflammation. The basic principles include the elimination the periimplant osseous defect using ostectomy and osteoplasty as well as bacterial decontamination (Figures 4 and 5). Additionally, smoothening and polishing of the supracrestal implant surface (implantoplasty) may be applied.

Serino et al. showed that in patients with active periimplant disease surgical pocket elimination and bone recontouring in combination with plaque control before and after surgery represents an effective treatment. Two years after open reduction of inflammated peri-implant soft tissue and osseous surgery $48 \%$ of the patients had no signs of peri-implantitis and $77 \%$ of the patients had

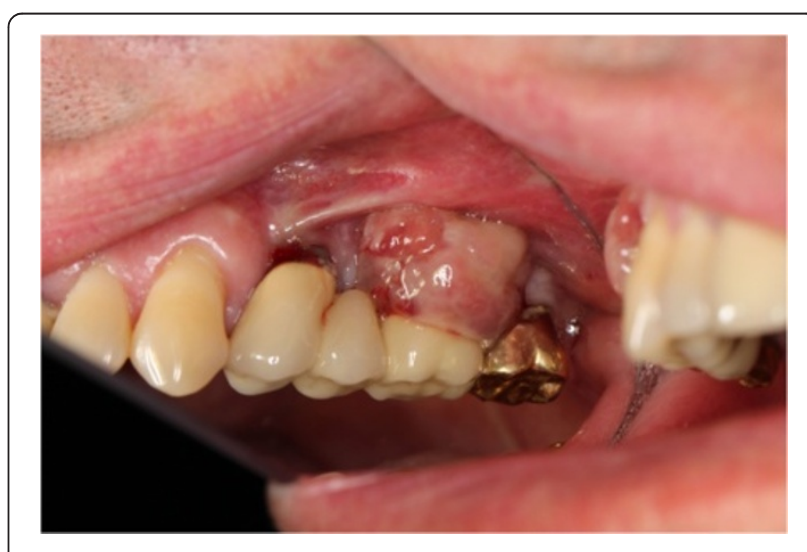

Figure 4 Peri-implantitis with granulation tissue. 


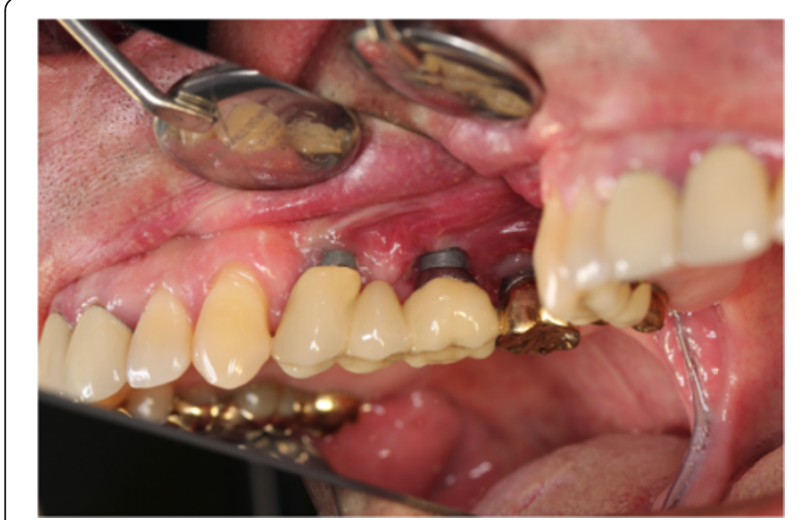

Figure 5 Peri-implantation 1 week after resective therapy.

no implants with pocket depths $\geq 6 \mathrm{~mm}$ with bleeding and/or suppuration [56].

In a radiographic study with 3 years follow-up, Romeo et al. showed that the marginal bone loss after resective surgery with implantoplasty was significantly lower than after resective therapy only [55]. The group with additional implantoplasty also had significantly lower probing pocket depths, probing attachment levels and modified bleeding indices after 24 months [54].

Adjuvant implant surface decontamination with antimicrobial substances led to an initially less anaerobic bacteria contamination, but did not improve the clinical outcome [75].

Resective surgical therapy for peri-implantitis is a recommendable therapy option. Ostectomy and osteoplasty combined with implantoplasty represent an effective therapy to reduce or even stop peri-implantitis progression. Nevertheless, due to the increased postoperative recessions, this procedure is not suitable for every situation, especially in highly esthetic sensitive areas.

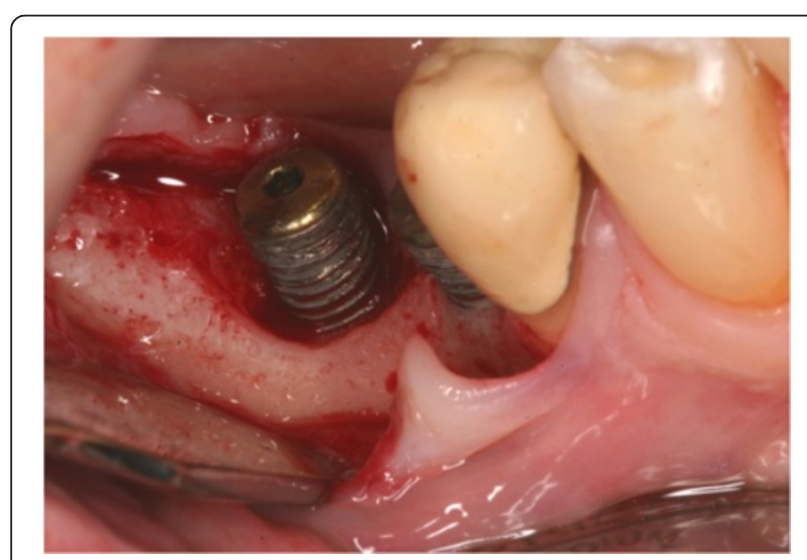

Figure 6 Regenerative therapie - defect after degranulation.

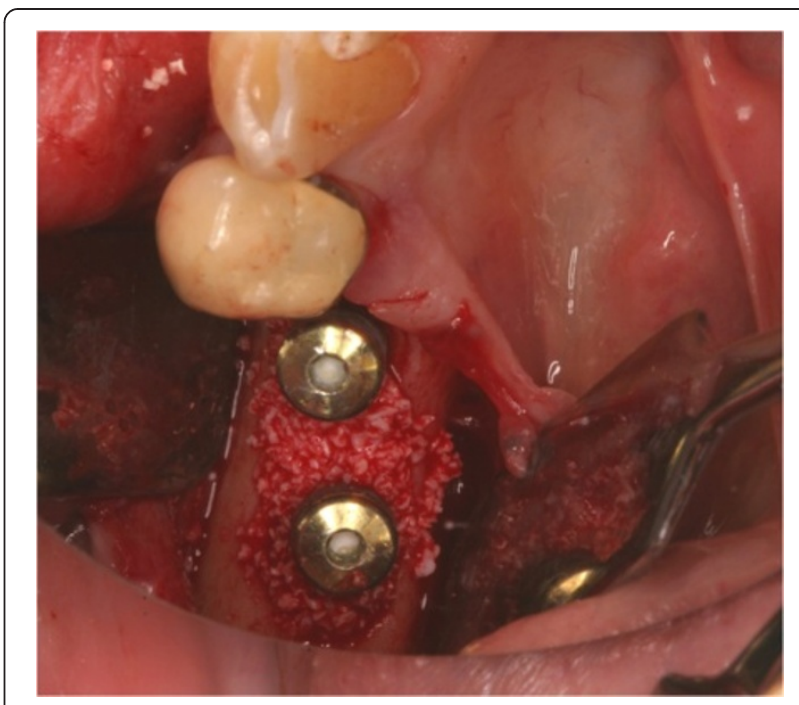

Figure 7 Regenerative therapie - defect fill with a xenograft material (BioOss ${ }^{\circledR}$, Geistlich, Switzerland).

\section{Regenerative approaches}

Resective surgical therapy may result in re-osseointegration in only minor superficial defects. From functional, esthetic and long-time-survival point of views, full regeneration and re-osseointegration is aspired. In animal models it was possible to regenerate experimentally induced defects using various graft materials and/or resorbable membranes following the principles of guided bone regeneration (GBR) (Figures 6, 7, 8, 9 and 10).

In a study by Hürzeler et al. in 1997 in dogs, there was no significant difference between the application of membranes only versus membranes in combination

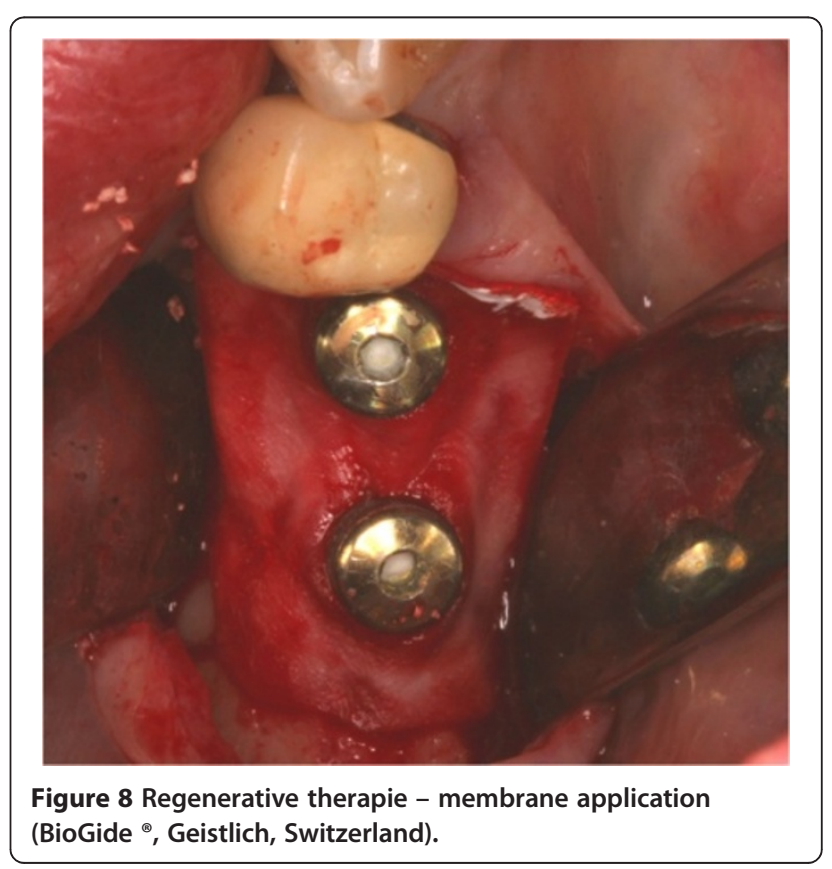




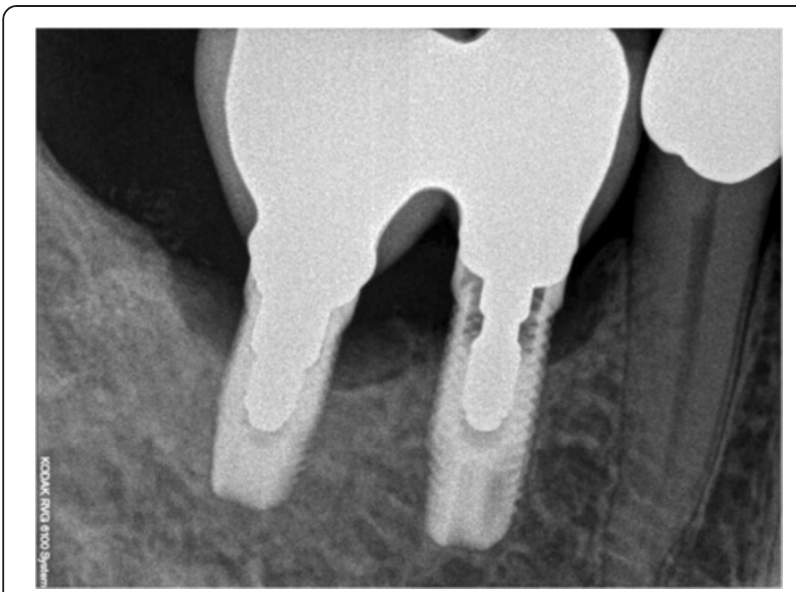

Figure 9 Preoperative radiograph of the peri-implant defect.

with bone grafts (canine demineralized freeze-dried bone or hydroxyapatite) in terms of bone regeneration. However, the combination resulted in a greater amount of re-osseointegration [95]. No statistical differences in reosseointegration could be demonstrated after treatment with GBR using a e-PTFE reinforced membrane compared to sites without this membrane [96]. The treatment resulted in $60-80 \%$ bone fill of the bony defect, but the absolute amount of re-osseointegration was small (between $0.1-0.6 \mathrm{~mm}$ ).

In contrast to debridement with surface decontamination, in most of all animal studies regenerative methods were reported as more efficient. In general, GBR alone and bone fill alone have been shown to be more effective than debridement alone regarding to bone regeneration and re-osseointegration. The results of studies using a combination of membranes and bone graft materials were superior to those using membranes or bone grafts alone and tend to give the best results, However, there is

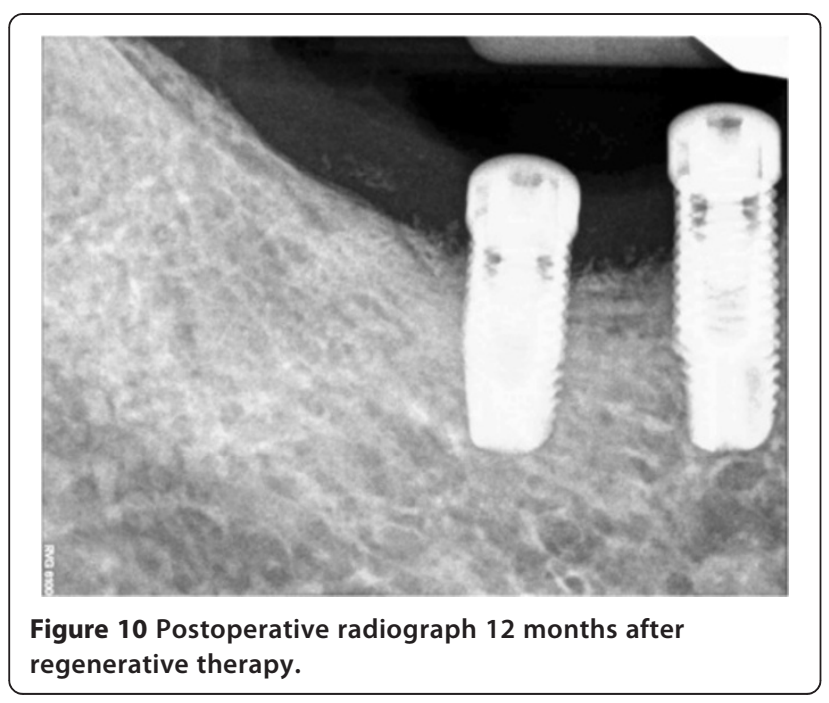

a high variability in the amount of bone fill due to different investigation protocols and measurements [97-99] and not in all studies there was a benefit for these treatments compared to debridement alone [100-102]. The role of submerged healing in peri-implantitis has not been solved clearly. Although Singh et al. demonstrated in 1993 greater bone regeneration and re-osseointegration during submerged healing, Grunder et al. found no differences between either healing method $[103,104]$.

Additionally, there are numerous studies regarding the treatment of peri-implantitis in humans under regenerative aspects. In a retrospective study of Lagervall et al. with 150 patients (382 implants) the most widely used operative intervention was the periodontal flap with osteoplasty (47\%), followed by the use of bone replacement materials (20\%). A cumulative success rate of $69 \%$ was recorded for both procedures, which was significantly lower in patients with risk factors such as smoking, periodontal disease and poor oral hygiene [29]. Regarding to a "regenerative" approach, autologous, allogenic and xenogenic bone replacement materials are often used for augmentation in bone defects used with or without collagen membrane. Allogenic and xenogenic grafts may be almost equivalent to autogenous material [105-107]. Schwarz et al. treated 22 patients randomly with access flap surgery and the application of nanocrystalline hydroxyapatite in contrast to xenogenic bone material with collagen membrane. No significant differences were determined between the groups, but 6 months after surgery both treatments resulted in clinically relevant reductions in probing depths and gains of clinical attachment level [108]. Roos-Jansåker et al. came to similar results using a coralline xenograft [19]. In another study bovinederived xenogenic material was compared with autogenous bone as filling material for infracrestal defects. The xenograft provided radiologically more bone fill and decreases in pocket depths, while bleeding on probing and suppuration were observed at both procedures [109]. In a prospective study, 36 cases of peri-implant bone loss were treated after local disinfection and removal of granulation tissue with a 1:1 mixture of autologous bone and a xenogenic bone graft. The result was a mean radiologically reduction of $3.5 \mathrm{~mm}$ from $5.1 \mathrm{~mm}$ one year after treatment with an average reduction of probing depths of $4 \mathrm{~mm}$ [59]. In a recent prospective case series a combined resective and regenerative approach including a bovine bone mineral and a collagen membrane infracrestally and implantoplasty supracrestally showed a significant peri-implant probing depth reduction and an increased radiographic defect fill after 12 months of followup [110]. In another study of Schwarz et al. defect cleaning with either Er:YAG laser or plastic curettes/cotton pellets with saline was combined with regenerative surgical procedures (xenogenic bone substitute and collagen membrane). 
Thereby, the clinical outcome did not differ according to the chosen method of surface debridement [111].

In purpose of bone regeneration various approaches have been described with various success rates. There is a tendency that xenograft materials in combination with a resorbable membranes might have advantages in terms of re-osseointegration. Nevertheless, because of the lack of prospective randomized clinical studies there is no evident data concerning the long-time stability of such "defect fillings".

\section{Conclusion}

Due to the lack of prospective randomized long-term follow-up studies lots of approaches but no "ideal periimplantitis therapy" have been described. There are many studies with different study designs in different populations with different materials used, but the sample sizes are often too small and the follow-up is too short. Therefore, prevention is the most important instrument based on appropriate treatment planning, an atraumatic approach for implant insertion and continuous check-up intervals with professional teeth and implant cleaning. Above all, attention should be paid to risk factors such as smoking and active or previous periodontitis. In non-surgical therapy, combinations of mechanical cleaning with curettes and air polishing systems are recommendable. Adjuvant antiseptic rinses and local or systemic antibiotics are effective for short-term bacteria eradication; laser and photodynamic therapy are additional treatment options. However, results for longterm benefits for these methods are missing.

Surgical therapy with resective and augmentative procedures completes the treatment options. Resective surgery can be used in order to eliminate peri-implant defects, to re-establish hygienic abilities and to reduce or even stop peri-implantitis progression. Regenerative approaches, e.g. with xenograft materials in combination with a resorbable membranes, are promising. The results of bone replacement materials and autologous bone grafts might be considered as nearly equivalent although long-term studies are still missing and only few studies with autologous bone material exist.

A graded systematic treatment planning according to the CIST protocol can be recommended. The "ideal peri-implantitis therapy", actually, is a sum of approaches leading to an individual therapy regime concerning multifactorial etiology, treatment options and study results.

\section{Consent}

Written informed consent was obtained from the patients for the publication of this report and any accompanying images.
Competing interests

The authors declare that they have no competing interests.

\section{Authors' contributions}

The research has been carried out equally by $\mathrm{RS}, \mathrm{AH}$ and OJ. JMS and $\mathrm{MH}$ supervised and corrected the manuscript. $\mathrm{CH}$ provided and edited the photographs. All authors read and approved the final manuscript.

\section{Author details}

${ }^{1}$ Department of Oral and Maxillofacial Surgery, University Medical Center Hamburg-Eppendorf, Martinistr. 52, 20246 Hamburg, Germany. ${ }^{2}$ Private Practice, Schumacherstrasse 14, 52062 Aachen, Germany. ${ }^{3}$ Department of Conservative Dentistry, Periodontology and Preventive Dentistry, University Hospital Aachen, Pauwelsstr.30, 52074 Aachen, Germany.

Received: 9 June 2014 Accepted: 15 August 2014

Published: 3 September 2014

\section{References}

1. Simonis $P$, Dufour $T$, Tenenbaum H: Long-term implant survival and success: a 10-16-year follow-up of non-submerged dental implants. Clin Oral Implants Res 2010, 21:772-777.

2. Khammissa RAG, Feller L, Meyerov R, Lemmer J: Peri-implant mucositis and peri-implantitis: clinical and histopathological characteristics and treatment. SADJ 2012, 67(122):124-126.

3. Zitzmann NU, Walter C, Berglundh T: Ätiologie, Diagnostik und Therapie der Periimplantitis - eine Übersicht. Deutsche Zahnärztliche Zeitschrift 2006, 61:642-649.

4. Wilson V: An insight into peri-implantitis: a systematic literature review. Prim Dent J 2013, 2:69-73.

5. Schwarz F, Sahm N, Becker J: Aktuelle Aspekte zur Therapie periimplantärer Entzündungen. Quintessenz 2008, 59:00.

6. Periimplantäre Entzündungen. [http://www.zwp-online.info/de/ fachgebiete/oralchirurgie/problemmanagement/periimplantaereentzuendungen]

7. Mombelli A, Muller N, Cionca N: The epidemiology of peri-implantitis. Clin Oral Implants Res 2012, 23(Suppl 6):67-76.

8. Hammerle $\mathrm{CH}$, Bragger U, Burgin W, Lang NP: The effect of subcrestal placement of the polished surface of ITI implants on marginal soft and hard tissues. Clin Oral Implants Res 1996, 7:111-119.

9. Spiekermann H: Implantologie. Stuttgart: Thieme; 1984.

10. Degidi M, Artese L, Piattelli A, Scarano A, Shibli JA, Piccirilli M, Perrotti V, lezzi G: Histological and immunohistochemical evaluation of the periimplant soft tissues around machined and acid-etched titanium healing abutments: a prospective randomised study. Clin Oral Investig 2012, 16:857-866

11. Xu L, Yu Z, Lee H-M, Wolff MS, Golub LM, Sorsa T, Kuula H: Characteristics of collagenase-2 from gingival crevicular fluid and peri-implant sulcular fluid in periodontitis and peri-implantitis patients: pilot study. Acta Odontol Scand 2008, 66:219-224.

12. Sorsa T, Tervahartiala T, Leppilahti J, Hernandez M, Gamonal J, Tuomainen AM, Lauhio A, Pussinen PJ, Mäntylä P: Collagenase-2 (MMP-8) as a point-of-care biomarker in periodontitis and cardiovascular diseases. Therapeutic response to non-antimicrobial properties of tetracyclines. Pharmacol Res 2011, 63:108-113.

13. Sorsa T, Hernández M, Leppilahti J, Munjal S, Netuschil L, Mäntylä P: Detection of gingival crevicular fluid MMP-8 levels with different laboratory and chair-side methods. Oral Dis 2010, 16:39-45.

14. Hall J, Britse $\mathrm{AO}$, Jemt $\mathrm{T}$, Friberg $\mathrm{B}$ : A controlled clinical exploratory study on genetic markers for peri-implantitis. Eur J Oral Implantol 2011, 4:371-382.

15. Atieh MA, Alsabeeha NHM, Faggion CM, Duncan WJ: The frequency of peri-implant diseases: a systematic review and meta-analysis. J Periodontol 2012, 84:586-598.

16. Charyeva O, Altynbekov K, Zhartybaev R, Sabdanaliev A: Long-term dental implant success and survival-a clinical study after an observation period up to 6 years. Swed Dent J 2012, 36:1-6.

17. Implantatoberflächen - Stand der Technik. [http://www.zmk-aktuell.de/ zahnheilkunde/implantologie/story/implantatoberflaechen-stand-dertechnik-teil-1.html]

18. Zitzmann NU, Berglundh T: Definition and prevalence of peri-implant diseases. J Clin Periodontol 2008, 35:286-291. 
19. Roos-Jansåker A-M, Renvert H, Lindahl C, Renvert S: Surgical treatment of peri-implantitis using a bone substitute with or without a resorbable membrane: a prospective cohort study. J Clin Periodontol 2007, 34:625-632.

20. Behrens E, Kolenda I, Terheyden H, Wiltfang J: Langzeitergebnisse des ITI-Implantatsystems. Implantologie 2004, 12:133-147.

21. Lindhe J, Meyle J: Peri-implant diseases: consensus report of the sixth european workshop on periodontology. J Clin Periodontol 2008, 35:282-285.

22. Rams TE, Degener JE, van Winkelhoff AJ: Antibiotic resistance in human peri-implantitis microbiota. Clin Oral Implants Res 2013, 25:82-90.

23. Charalampakis G, Leonhardt A, Rabe P, Dahlen G: Clinical and microbiological characteristics of peri-implantitis cases: a retrospective multicentre study. Clin Oral Implants Res 2012, 23:1045-1054.

24. Salvi GE, Fürst MM, Lang NP, Persson GR: One-year bacterial colonization patterns of Staphylococcus aureus and other bacteria at implants and adjacent teeth. Clin Oral Implants Res 2008, 19:242-248.

25. Subramani K, Jung RE, Molenberg A, Hammerle CHF: Biofilm on dental implants: a review of the literature. Int J Oral Maxillofac Implants 2009, 24:616-626.

26. Heitz-Mayfield LJA: Peri-implant diseases: diagnosis and risk indicators. J Clin Periodontol 2008, 35:292-304.

27. Gruica B, Wang H-Y, Lang NP, Buser D: Impact of IL-1 genotype and smoking status on the prognosis of osseointegrated implants. Clin Oral Implants Res 2004, 15:393-400.

28. Huynh-Ba G, Lang NP, Tonetti MS, Zwahlen M, Salvi GE: Association of the composite IL-1 genotype with peri-implantitis: a systematic review. Clin Oral Implants Res 2008, 19:1154-1162.

29. Lagervall M, Jansson LE: Treatment outcome in patients with peri-implantitis in a periodontal clinic- a retrospective study. J Periodontol 2012, 84:1365-1373.

30. Linkevicius T, Puisys A, Vindasiute E, Linkeviciene L, Apse P: Does residual cement around implant-supported restorations cause peri-implant disease? A retrospective case analysis. Clin Oral Implants Res 2012, 24:1179-1184.

31. Vervaeke S, Collaert B, Cosyn J, Deschepper E, De Bruyn H: A multifactorial analysis to identify predictors of implant failure and peri-implant bone loss. Clin Implant Dent Relat Res 2013. doi:10.1111/cid.12149 [Epub ahead of print].

32. Renvert S, Aghazadeh A, Hallstrom H, Persson GR: Factors related to periimplantitis - a retrospective study. Clin Oral Implants Res 2014, 25:522-529.

33. Ferreira SD, Silva GL, Cortelli JR, Costa JE, Costa FO: Prevalence and risk variables for peri-implant disease in Brazilian subjects. J Clin Periodontol 2006, 33:929-935.

34. Clementini M, Rossetti PH, Penarrocha D, Micarelli C, Bonachela WC, Canullo $L$ : Systemic risk factors for peri-implant bone loss: a systematic review and meta-analysis. Int J Oral Maxillofac Surg 2014, 43:323-334.

35. Kasat V, Ladda R: Smoking and dental implants. J Int Soc Prev Commun Dent 2012, 2:38-41.

36. Sgolastra F, Petrucci A, Severino M, Gatto R, Monaco A: Smoking and the risk of peri-implantitis. A systematic review and meta-analysis. Clin Oral Implants Res 2014. doi:10.1111/clr.12333 [Epub ahead of print]

37. Koldsland OC, Scheie AA, Aass AM: The association between selected risk indicators and severity of peri-implantitis using mixed model analyses. J Clin Periodontol 2011, 38:285-292.

38. Karbach J, Callaway A, Kwon YD, d'Hoedt B, Al-Nawas B: Comparison of five parameters as risk factors for peri-mucositis. Int J Oral Maxillofac Implants 2009, 24:491-496.

39. Brito C, Tenenbaum HC, Wong BK, Schmitt C, Nogueira-Filho G: Is keratinized mucosa indispensable to maintain peri-implant health? A systematic review of the literature. J Biomed Mater Res B App/ Biomater 2014, 102:643-650.

40. Malo P, Rigolizzo M, Nobre M, Lopes A, Agliardi E: Clinical outcomes in the presence and absence of keratinized mucosa in mandibular guided implant surgeries: a pilot study with a proposal for the modification of the technique. Quintessence Int 2013, 44:149-157.

41. Wennstrom JL, Derks J: Is there a need for keratinized mucosa around implants to maintain health and tissue stability? Clin Oral Implants Res 2012, 23(Suppl 6):136-146.

42. Wilson TG Jr: The positive relationship between excess cement and peri-implant disease: a prospective clinical endoscopic study. J Periodontol 2009, 80:1388-1392.

43. Korsch M, Obst U, Walther W: Cement-associated peri-implantitis: a retrospective clinical observational study of fixed implant-supported restorations using a methacrylate cement. Clin Oral Implants Res 2014 25:797-802.
44. Al-Nsour MM, Chan H-L, Wang H-L: Effect of the platform-switching technique on preservation of peri-implant marginal bone: a systematic review. Int J Oral Maxillofac Implants 2012, 27:138-145.

45. Vandeweghe S, De Bruyn $\mathrm{H}$ : A within-implant comparison to evaluate the concept of platform switching: a randomised controlled trial. Eur J Oral Implantol 2012, 5:253-262.

46. Flanagan D, llies H, Lasko B, Stack J: Force and movement of Non-osseointegrated implants: an in vitro study. J Oral Implantol 2009, 35:270-276.

47. Mahnama A, Tafazzoli-Shadpour M, Geramipanah F, Mehdi Dehghan M: Verification of the mechanostat theory in mandible remodeling after tooth extraction: Animal study and numerical modeling. J Mech Behav Biomed Mater 2013, 20:354-362.

48. Steigenga JT, al-Shammari KF, Nociti FH, Misch CE, Wang H-L: Dental implant design and its relationship to long-term implant success. Implant Dent 2003, 12:306-317.

49. Georgiopoulos B, Kalioras K, Provatidis C, Manda M, Koidis P: The effects of implant length and diameter prior to and after osseointegration: a 2-D finite element analysis. J Oral Implantol 2007, 33:243-256.

50. Heitz-Mayfield LJA, Salvi GE, Botticelli D, Mombelli A, Faddy M, Lang NP. Anti-infective treatment of peri-implant mucositis: a randomised controlled clinical trial. Clin Oral Implants Res 2011, 22:237-241.

51. Hallström H, Persson GR, Lindgren S, Olofsson M, Renvert S: Systemic antibiotics and debridement of peri-implant mucositis. A randomized clinical trial. J Clin Periodontol 2012, 39:574-581.

52. Zeza B, Pilloni A: Peri-implant mucositis treatments in humans: a systematic review. Ann Stomatol 2012, 3:83-89.

53. Renvert S, Polyzois I, Claffey N: Surgical therapy for the control of periimplantitis. Clin Oral Implants Res 2012, 23(Suppl 6):84-94.

54. Romeo E, Ghisolfi M, Murgolo N, Chiapasco M, Lops D, Vogel G: Therapy of peri-implantitis with resective surgery. A 3-year clinical trial on rough screw-shaped oral implants. Part I: clinical outcome. Clin Oral Implants Res 2005, 16:9-18.

55. Romeo E, Lops D, Chiapasco M, Ghisolfi M, Vogel G: Therapy of periimplantitis with resective surgery. A 3-year clinical trial on rough screw-shaped oral implants. Part II: radiographic outcome. Clin Oral Implants Res 2007, 18:179-187.

56. Serino G, Turri A: Outcome of surgical treatment of peri-implantitis: results from a 2-year prospective clinical study in humans. Clin Oral Implants Res 2011, 22:1214-1220.

57. Thierbach R, Eger T: Clinical outcome of a nonsurgical and surgical treatment protocol in different types of peri-implantitis: a case series. Quintessence Int 2013, 44:137-148.

58. Roccuzzo M, Bonino F, Bonino L, Dalmasso P: Surgical therapy of peri-implantitis lesions by means of a bovine-derived xenograft: comparative results of a prospective study on two different implant surfaces. J Clin Periodontol 2011, 38:738-745

59. Wiltfang J, Zernial O, Behrens E, Schlegel A, Warnke PH, Becker ST: Regenerative treatment of peri-implantitis bone defects with a combination of autologous bone and a demineralized xenogenic bone graft: a series of 36 defects. Clin Implant Dent Relat Res 2012, 14:421-427.

60. Augthun $M$, Tinschert J, Huber A: In vitro studies on the effect of cleaning methods on different implant surfaces. J Periodontol 1998, 69:857-864.

61. Unursaikhan O, Lee JS, Cha JK, Park JC, Jung UW, Kim CS, Cho KS, Choi SH: Comparative evaluation of roughness of titanium surfaces treated by different hygiene instruments. J Periodontal Implant Sci 2012,42:88-94

62. Karring ES, Stavropoulos A, Ellegaard B, Karring T: Treatment of periimplantitis by the Vector system. Clin Oral Implants Res 2005, 16:288-293.

63. Renvert S, Samuelsson E, Lindahl C, Persson GR: Mechanical non-surgical treatment of peri-implantitis: a double-blind randomized longitudinal clinical study. I: clinical results. J Clin Periodontol 2009, 36:604-609.

64. Tastepe CS, Liu Y, Visscher CM, Wismeijer D: Cleaning and modification of intraorally contaminated titanium discs with calcium phosphate powder abrasive treatment. Clin Oral Implants Res 2012, 24:1238-1246.

65. Tastepe CS, van Waas R, Liu Y, Wismeijer D: Air powder abrasive treatment as an implant surface cleaning method: a literature review. Int J Oral Maxillofac Implants 2012, 27:1461-1473.

66. Persson GR, Samuelsson E, Lindahl C, Renvert S: Mechanical non-surgical treatment of peri-implantitis: a single-blinded randomized longitudinal clinical study. II. Microbiological results. J Clin Periodontol 2010, 37:563-573.

67. Sahm N, Becker J, Santel T, Schwarz F: Non-surgical treatment of peri-implantitis using an air-abrasive device or mechanical 
debridement and local application of chlorhexidine: a prospective, randomized, controlled clinical study. J Clin Periodontol 2011, 38:872-878

68. Louropoulou A, Slot DE, van der Weijden F: The effects of mechanical instruments on contaminated titanium dental implant surfaces: a systematic review. Clin Oral Implants Res 2013. doi:10.1111/dr.12224 [Epub ahead of print].

69. Javed F, Alghamdi AST, Ahmed A, Mikami T, Ahmed HB, Tenenbaum HC Clinical efficacy of antibiotics in the treatment of peri-implantitis. Int Dent J 2013, 63:169-176.

70. Moura LA, Oliveira Giorgetti Bossolan AP, Rezende Duek EA, Sallum EA, Nociti FH, Casati MZ, Sallum AW: Treatment of peri-implantitis using nonsurgical debridement with bioresorbable nanospheres for controlled release of doxycycline: case report. Compend Contin Educ Dent (Jamesburg, NJ : 1995) 2012, 33:E145-E149.

71. Leonhardt A, Dahlén G, Renvert S: Five-year clinical, microbiological, and radiological outcome following treatment of peri-implantitis in man. J Periodontol 2003, 74:1415-1422.

72. Astasov-Frauenhoffer M, Braissant O, Hauser-Gerspach I, Weiger R, Walter C Zitzmann NU, Waltimo T: Microcalorimetric determination of the effects of amoxicillin, metronidazole and their combination on an in vitro biofilm. J Periodontol 2014, 85:349-357.

73. Bassetti M, Schär D, Wicki B, Eick S, Ramseier CA, Arweiler NB, Sculean A, Salvi GE: Anti-infective therapy of peri-implantitis with adjunctive local drug delivery or photodynamic therapy: 12-month outcomes of a randomized controlled clinical trial. Clin Oral Implants Res 2013, 25:279-287.

74. Shrestha B, Theerathavaj MLS, Thaweboon S, Thaweboon B: In vitro antimicrobial effects of grape seed extract on peri-implantitis microflora in craniofacial implants. Asian Pac J Trop Biomed 2012, 2:822-825.

75. Waal YCM, Raghoebar GM, Huddleston Slater JJR, Meijer HJA, Winkel EG, van Winkelhoff AJ: Implant decontamination during surgical periimplantitis treatment: a randomized, double-blind, placebo-controlled trial. J Clin Periodontol 2013, 40:186-195.

76. Machtei EE, Frankenthal S, Levi G, Elimelech R, Shoshani E, Rosenfeld O, Tagger-Green N, Shlomi B: Treatment of peri-implantitis using multiple applications of chlorhexidine chips: a double-blind, randomized multi-centre clinical trial. J Clin Periodontol 2012, 39:1198-1205.

77. Di Carlo F, Quaranta A, Di Alberti L, Ronconi LF, Quaranta M, Piattelli A: Influence of amine fluoride/stannous fluoride mouthwashes with and without chlorhexidine on secretion of proinflammatory molecules by peri-implant crevicular fluid cells. Minerva Stomatol 2008, 57:215-221. 221-215.

78. Renvert S, Lessem J, Dahlén G, Lindahl C, Svensson M: Topical minocycline microspheres versus topical chlorhexidine gel as an adjunct to mechanical debridement of incipient peri-implant infections: a randomized clinical trial. J Clin Periodontol 2006, 33:362-369.

79. Lan S-F, Kehinde T, Zhang X, Khajotia S, Schmidtke DW, Starly B: Controlled

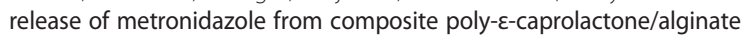
(PCL/alginate) rings for dental implants. Dent Mater 2013, 29:656-665.

80. Hou J, Li C, Cheng L, Guo S, Zhang Y, Tang T: Study on hydrophilic 5fluorouracil release from hydrophobic poly( $\varepsilon$-caprolactone) cylindrical implants. Drug Dev Ind Pharm 2011, 37:1068-1075.

81. Muthukuru M, Zainvi A, Esplugues EO, Flemmig TF: Non-surgical therapy for the management of peri-implantitis: a systematic review. Clin Oral Implants Res 2012, 23(Suppl 6):77-83.

82. Yamamoto A, Tanabe T: Treatment of peri-implantitis around TiUnitesurface implants using Er:YAG laser microexplosions. Int $J$ Periodontics Restorative Dent 2013, 33:21-30.

83. Schwarz F, Rothamel D, Becker J: Einfluss eines Er:YAG-Lasers auf die Oberflächenstruktur von Titanimplantaten. Klinische Fallberichte. Schweiz Monatsschr Zahnmed 2003, 113:660-671

84. Deppe H, Horch H-H, Schrödl V, Haczek C, Miethke T: Effect of 308-nm excimer laser light on peri-implantitis-associated bacteria: an in vitro investigation. Lasers Med Sci 2007, 22:223-227.

85. Schwarz F, Sculean A, Rothamel D, Schwenzer K, Georg T, Becker J: Clinical evaluation of an Er:YAG laser for nonsurgical treatment of periimplantitis: a pilot study. Clin Oral Implants Res 2005, 16:44-52.

86. Persson GR, Roos-Jansåker A-M, Lindahl C, Renvert S: Microbiologic results after non-surgical erbium-doped:yttrium, aluminum, and garnet laser or air-abrasive treatment of peri-implantitis: a randomized clinical trial. J Periodontol 2011, 82:1267-1278.
87. Mailoa J, Lin GH, Chan HL, Maceachern M, Wang HL: Clinical outcomes of using lasers for peri-implantitis surface detoxification: a systematic review and meta-analysis. J Periodontol 2014, [Epub ahead of print].

88. Al-Ahmad A, Tennert C, Karygianni L, Wrbas KT, Hellwig E, Altenburger MJ: Antimicrobial photodynamic therapy using visible light plus waterfiltered infrared-A (wIRA). J Med Microbiol 2013, 62:467-473.

89. Meisel P, Kocher T: Photodynamic therapy for periodontal diseases: state of the art. J Photochem Photobiol B 2005, 79:159-170.

90. Deppe H, Mücke T, Wagenpfeil S, Kesting M, Sculean A: Nonsurgical antimicrobial photodynamic therapy in moderate vs severe peri-implant defects: A clinical pilot study. Quintessence Int (Berlin, Germany: 1985) 2013, 44:609-618.

91. Mombelli A: Etiology, diagnosis, and treatment considerations in peri-implantitis. Curr Opin Periodontol 1997, 4:127-136.

92. Mombelli A, Lang NP: The diagnosis and treatment of peri-implantitis. Periodontol 2000 1998, 17:63-76.

93. Lang NP, Berglundh T, Heitz-Mayfield L, Pjetursson BE, Salvi GE, Sanz M: Consensus statements and recommended clinical procedures regarding implant survival and complications. Int I Oral Maxillofac Implants 2004, 19(Suppl):150-154.

94. Schmage P: Befundorientiertes Behandlungskonzept bei periimplantären Infektionen. Parodontol 2010, 21:339-358.

95. Hurzeler MB, Quinones CR, Schupback P, Morrison EC, Caffesse RG Treatment of peri-implantitis using guided bone regeneration and bone grafts, alone or in combination, in beagle dogs. Part 2: Histologic findings. Int J Oral Maxillofac Implants 1997, 12:168-175.

96. Wetzel AC, Vlassis J, Caffesse RG, Hammerle CH, Lang NP: Attempts to obtain re-osseointegration following experimental peri-implantitis in dogs. Clin Oral Implants Res 1999, 10:111-119.

97. Claffey N, Clarke E, Polyzois I, Renvert S: Surgical treatment of peri-implantitis. J Clin Periodontol 2008, 35:316-332.

98. Machado MA, Stefani CM, Sallum EA, Sallum AW, Tramontina VA, Nocit Junior FH: Treatment of ligature-induced peri-implantitis defects by regenerative procedures: a clinical study in dogs. J Oral Sci 1999, 41:181-185

99. Machado MA, Stefani CM, Sallum EA, Sallum AW, Tramontina VA, NogueiraFilho GR, Nociti Junior FH: Treatment of ligature-induced peri-implantitis defects by regenerative procedures. Part II: A histometric study in dogs. J Oral Sci 2000, 42:163-168.

100. Nociti FH Jr, Caffesse RG, Sallum EA, Machado MA, Stefani CM, Sallum AW: Evaluation of guided bone regeneration and/or bone grafts in the treatment of ligature-induced peri-implantitis defects: a morphometric study in dogs. J Oral Implantol 2000, 26:244-249.

101. Nociti FH Jr, Machado MA, Stefani CM, Sallum EA: Absorbable versus nonabsorbable membranes and bone grafts in the treatment of ligatureinduced peri-implantitis defects in dogs: a histometric investigation. Int J Oral Maxillofac Implants 2001, 16:646-652.

102. Nociti FH Jr, Machado MA, Stefani CM, Sallum EA, Sallum AW: Absorbable versus nonabsorbable membranes and bone grafts in the treatment of ligature-induced peri-implantitis defects in dogs. Part I. A clinical investigation. Clin Oral Implants Res 2001, 12:115-120.

103. Grunder U, Hurzeler MB, Schupbach P, Strub JR: Treatment of ligatureinduced peri-implantitis using guided tissue regeneration: a clinical and histologic study in the beagle dog. Int J Oral Maxillofac Implants 1993, 8:282-293.

104. Singh G, O'Neal RB, Brennan WA, Strong SL, Horner JA, Van Dyke TE: Surgical treatment of induced peri-implantitis in the micro pig: clinical and histological analysis. J Periodontol 1993, 64:984-989.

105. Osteokonduktive und -induktive Knochenersatzmaterialien. [http://www zmk-aktuell.de/zahnheilkunde/implantologie/story/osteokonduktive-undinduktive-knochenersatzmaterialien-teil-1.html].

106. Kolk A, Handschel J, Drescher W, Rothamel D, Kloss F, Blessmann M, Heiland $M$, Wolff K-D, Smeets R: Current trends and future perspectives of bone substitute materials - From space holders to innovative biomaterials. J Craniomaxillofac Surg 2012, 40:706-718.

107. Fischer J, Kolk A, Wolfart S, Pautke C, Warnke PH, Plank C, Smeets R: Future of local bone regeneration - Protein versus gene therapy. J Craniomaxillofac Surg 2011, 39:54-64.

108. Schwarz F, Bieling K, Latz T, Nuesry E, Becker J: Healing of intrabony periimplantitis defects following application of a nanocrystalline hydroxyapatite (Ostim) or a bovine-derived xenograft (Bio-Oss) in combination 
with a collagen membrane (Bio-Gide). A case series. J Clin Periodontol 2006, 33:491-499.

109. Aghazadeh A, Rutger Persson G, Renvert S: A single-centre randomized controlled clinical trial on the adjunct treatment of intra-bony defects with autogenous bone or a xenograft: results after 12 months. J Clin Periodontol 2012, 39:666-673.

110. Matarasso S, lorio Siciliano V, Aglietta M, Andreuccetti G, Salvi GE: Clinical and radiographic outcomes of a combined resective and regenerative approach in the treatment of peri-implantitis: a prospective case series. Clin Oral Implants Res 2014, 25:761-767.

111. Schwarz F, John G, Mainusch S, Sahm N, Becker J: Combined surgical therapy of peri-implantitis evaluating two methods of surface debridement and decontamination. A two-year clinical follow up report. J Clin Periodontol 2012, 39:789-797.

doi:10.1186/1746-160X-10-34

Cite this article as: Smeets et al.: Definition, etiology, prevention and

treatment of peri-implantitis - a review. Head \& Face Medicine 2014 10:34.

\section{Submit your next manuscript to BioMed Central and take full advantage of:}

- Convenient online submission

- Thorough peer review

- No space constraints or color figure charges

- Immediate publication on acceptance

- Inclusion in PubMed, CAS, Scopus and Google Scholar

- Research which is freely available for redistribution 